\title{
A gestão do Sistema Único de Saúde no Brasil e as regiões de fronteira em pauta ${ }^{1}$
}

\author{
Lislei Teresinha Preuss ${ }^{1}$ \\ https://orcid.org/0000-0001-5786-7228 \\ ${ }^{1}$ Universidade Estadual de Ponta Grossa, Departamento de Serviço Social, Programa de Pós-Graduação em Ciências Sociais Aplicadas, \\ Ponta Grossa, PR, Brasil (UEPG)
}

\begin{abstract}
A gestão do Sistema Único de Saúde no Brasil e as regiões de fronteira em pauta
Resumo: Este artigo tem como objetivo apresentar, a partir de uma revisão bibliográfica de caráter histórico-crítica, os principais aspectos normativos da gestão do Sistema Único de Saúde (SUS) no Brasil, destacando o Pacto pela Saúde neste processo. O Pacto avança na perspectiva de apontar a regionalização como eixo estruturante da Gestão do SUS, considerando as regiões de fronteira. Buscase sintetizar os aspectos normativos da gestão da saúde pública no Brasil a partir da Constituição Federal de 1988 até a implantação do Pacto em 2016. Acredita-se que a Gestão do SUS tem o desafio de avançar na regionalização e descentralização deste sistema com base em seus princípios, operacionalizando-os de forma a respeitar as especificidades regionais, como as regiões de fronteiras. Diante disso, observam-se elementos de continuidade em relação às orientações e normativas anteriores, principalmente sobre o poder de regulação do Ministério da Saúde, e mudança ao contemplar na regionalização os territórios fronteiriços.

Palavras-chave: Gestão do SUS. Pacto pela Saúde. Regionalização. Regiões de Fronteiras.
\end{abstract}

The management of the Unified Health System in Brazil and the border regions in debate

Abstract: This article aims to present, from a bibliographical review of historical-critical nature, the main normative aspects of the management of the Unified Health System (SUS) in Brazil, highlighting the Pact for Health in this process. The Pact advances the perspective of regionalization as the structuring axis of SUS Management, considering the border regions. It seeks to synthesize the normative aspects of public health management in Brazil from the Federal Constitution of 1988 until the implementation of the Pact in 2016. It is believed that SUS Management has the challenge of advancing the regionalization and decentralization of this system based on their principles, operating in a way that respects regional specificities, such as border regions. Elements of continuity are observed in relation to the previous guidelines and regulations, mainly on the power of regulation of the Ministry of Health. Elements of change are found when contemplating in the regionalization the border territories.

Keywords: SUS Management. Pact for Health. Regionalization. Border Regions.

Recebido em 15.10.2017. Aprovado em 08.02.2018. Revisado em 15.03.2018.

\section{(ब) $\odot$ \&}

(C) O(s) Autor(es). 2018 Acesso Aberto Esta obra está licenciada sob os termos da Licença Creative Commons Atribuição-NãoComercial 4.0 Internacional (https://creativecommons.org/licenses/by-nc/4.0/deed.pt_BR), que permite copiar, distribuir e reproduzir em qualquer meio, bem como adaptar, transformar e criar a partir deste material, desde que para fins não comerciais e que você forneça o devido crédito aos autores e a fonte, insira um link para a Licença Creative Commons e indique se mudanças foram feitas. 


\section{Introdução}

Este artigo tem como objetivo apresentar, a partir de uma revisão bibliográfica, de caráter histórico-crítico, os principais aspectos normativos da gestão do Sistema Único de Saúde (SUS) no Brasil, tendo como marco a Constituição Federal de 1988 (BRASIL, 2016a), destacando diversos instrumentos e marcos regulatórios da gestão do SUS até a implantação do Pacto pela Saúde em 2016. O Pacto pela Saúde avança na perspectiva de apontar a regionalização como eixo estruturante da Gestão do SUS, contemplando, as regiões de fronteira (BRASIL, 2006a).

Eleger a gestão do SUS e as regiões de fronteiras como objeto de estudo e discussão pressupõe desvendar suas conexões, diretrizes políticas e sua operacionalização. Tal posicionamento requer a leitura e análise da realidade de forma crítica e o entendimento de política de saúde enquanto uma política social pública, com traços históricos determinantes, decorrentes de situações problemáticas e constitutivas de desigualdades econômico-sociais.

O método dialético orientou este estudo, em sua abordagem e discussão, resgatando o contexto histórico das relações sociais a partir das novas características do capital na contemporaneidade, das quais destacamse: globalização, neoliberalismo, privatização do fundo público e precarização das políticas sociais. A revisão bibliográfica permitiu ampliar e aprofundar o conhecimento sobre a temática delimitada.

Considera-se esta temática relevante e busca-se contribuir para ampliar a produção de conhecimento e debate sobre gestão da saúde pública - visto ser a primeira vez que uma resolução ministerial incluiu a fronteira como uma continuidade territorial - e incorpora o desafio das gestões locais em integrar ações que promovam, de fato, o acesso à saúde de estrangeiros residentes em municípios fronteiriços.

O conceito de gestão em saúde contempla questões de criação e de utilização de meios para concretizar os princípios de organização desta política. Nesse sentido, com a criação do SUS, o Ministério da Saúde assume a área e, para superar as lacunas constitucionais, edita as Normas Operacionais Básicas (NOBs). Por exemplo, a NOB 91 explicita o processo de municipalização (BRASIL, 1991); a NOB 93 caracterizou-se pela luta quanto ao financiamento do sistema (BRASIL, 1993); e a NOB 96 criou os diversos níveis de gestão (BRASIL, 1996). As Normas Operacionais de Assistência à Saúde (NOAS) foram responsáveis pela introdução das ferramentas de planejamento e programação em saúde: o Plano Diretor de Regionalização (PDR); o Plano Diretor de Investimentos (PDI) e a Programação Pactuada e Integrada (PPI). E, por fim, em 2006 é formulado o Pacto pela Saúde, firmado entre os gestores - União, Estados e Municípios, em três dimensões, pela Vida, em Defesa do SUS e de Gestão para Consolidação do SUS (BRASIL, 2006b, 2006c).

O Pacto é estabelecido com base nos princípios e diretrizes do SUS, considerando a diversidade e a realidade de cada região e estado brasileiro, enfatizando as necessidades de saúde da população. Estabelece um novo patamar em relação à forma de financiamento, à definição de responsabilidades, às metas sanitárias e aos compromissos entre os gestores da saúde, consubstanciados em termos de metas e plano operativo. Substitui os anteriores processos de habilitação criadas para operar as transformações previstas na Constituição e na Lei Orgânica da Saúde e também estabelece metas e compromissos para cada ente da federação.

Especificamente, a criação do bloco Gestão do SUS é a primeira iniciativa concreta aprovada, que estabelece financiamento destinado ao custeio de ações relacionadas com a organização do sistema de saúde: regulação, controle, avaliação e auditoria; planejamento e orçamento; programação; regionalização; participação e controle social; gestão do trabalho; educação em saúde e implementação de políticas específicas.

Para efeito de apresentação, este artigo está estruturado em dois momentos. No primeiro busca-se apresentar, de maneira descritiva, os principais aspectos normativos da gestão do SUS no Brasil a partir da Constituição Federal de 1988 (BRASIL, 2016a), perpassando as diversas orientações normativas, como a NOB 91, NOB 93, NOB 96 que contribuíram para a organização e gestão deste sistema (BRASIL, 1991, 1993, 1996). No segundo, contextualiza-se o Pacto pela Saúde, construído para dar respostas concretas aos desafios atuais da gestão e organização do sistema, às necessidades de saúde da população brasileira e, tornar a saúde uma política de Estado (BRASIL, 2006b). O Pacto pela Saúde, em suas três dimensões, tem como finalidade a qualificação da gestão pública do SUS, buscando maior efetividade, eficiência e qualidade de suas respostas (BRASIL, 2006c). Especificamente, destacam-se, o Pacto de Gestão do SUS e a regionalização, bem como o cenário atual e as principais tendências da gestão da política de saúde na contemporaneidade. E, por fim, apresentam-se algumas considerações sobre a temática aqui abordada.

\section{A gestão do SUS no Brasil - aspectos normativos}

O debate sobre as políticas sociais na perspectiva de sua democratização, no Brasil, tem origem no quadro político dos anos 1980 com as lutas contra a ditadura militar e os esforços pela construção democrática do Estado e da sociedade civil. Diante da crise do Estado autoritário, do agravamento da questão social na 
década de 1980 e da luta pela democratização do Estado e da sociedade, intensifica-se o debate sobre as políticas públicas, especialmente as de corte social.

Neste novo cenário, de redefinições das relações entre Estado e sociedade civil, um amplo e heterogêneo conjunto de forças sociais foi protagonista do debate e das propostas frente à crise social, desaguando no processo constituinte do qual resultou a Constituição Federal de 1988 (PREUSS, 2011).

A Constituição Federal de 1988 (BRASIL, 2016a) é um marco importante no campo das políticas sociais, especificamente na saúde, consagrou o direito à saúde e definiu princípios e diretrizes para orientá-la, como a garantia do acesso universal, igualitário e gratuito às ações e serviços de saúde. O SUS é a expressão institucional da política de saúde, redesenhando a estrutura do Estado em uma lógica de federação descentralizada, com ênfase no papel dos municípios. Também é um marco legal, um divisor de águas no sistema de gestão da saúde pública no Brasil, pois a partir desta Constituição, com a promulgação da Lei Orgânica da Saúde (Lei n ${ }^{\circ} 8.080$, de 19 de setembro de 1990, complementada pela Lei no 8.142, de 28 de dezembro de 1990 (BRASIL, 1990)), tem-se um novo conceito de gestão e direções de gestão das políticas públicas, sendo a saúde pioneira (PREUSS, 2011).

As mudanças introduzidas pela Constituição Federal de 1988 (BRASIL, 2016a) rompem com a tradição histórica de políticas sociais centralizadas, cabendo ao nível central de governo a definição das prioridades e da execução dos serviços de saúde pelos estados e municípios. O marco divisório que representou na história do sistema de gestão da saúde pública no Brasil, se formou a partir de dois elementos essenciais a universalidade e a descentralização.

O SUS foi construído com base no princípio fundamental da universalização, expresso na Saúde como direito de todos os brasileiros, a ser provida como dever de Estado, uma luta da reforma sanitária brasileira, incorporada na Constituição Federal de 1988 (BRASIL, 2016a). O princípio da universalização caracteriza-se pela oferta a todos os cidadãos, ações e serviços na área da saúde, ou seja, todos os brasileiros têm direito aos serviços do SUS e o acesso universal não pode ser restringido. A descentralização em saúde no Brasil é políticoadministrativa, abrange não apenas a transferência da gestão de serviços públicos, mas também de poder decisório, da responsabilidade sobre o conjunto de prestadores do SUS e de recursos financeiros (PREUSS, 2011).

Com a institucionalização do SUS, o modelo organizacional do sistema de saúde brasileiro perdeu sua tendência estadualista desenhada pelo Sistema Unificado e Descentralizado de Saúde(SUDS), passando a municipalização a se constituir no eixo condutor do processo de descentralização do sistema. O sistema de alocação de recursos no âmbito do SUS começou a ser desenhado por Normas Operacionais (UGÁ; MARQUES, 2005).

A NOB e a NOAS estabelecem as diretrizes para a operacionalização do SUS, detalhando a legislação da saúde, e têm como tarefa consolidar o exercício das funções de gestão e do gerenciamento da instituição que disponibiliza os serviços aos seus habitantes. São definidas pelas Comissões Intergestora Tripartite e (CIT)e Intergestora Bipartite (CIB), promovendo o processo de descentralização, determinando mecanismos para a transferência automática de recursos federais aos estados e municípios e fortalecendo os processos de gestão compartilhada entre as esferas.

A NOB 91 (BRASIL, 1991), editada pela Presidência do Instituto Nacional de Assistência Médica da Previdência Social (INAMPS), foi escrita segundo a cultura prevalecente naquela instituição de assistência médica. Com forte conotação centralizadora, objetivou regularizar o processo de descentralização políticoadministrativa, estabelecendo parâmetros para sua garantia, responsabilidades e critérios de financiamento das ações e serviços, instituindo um sistema de alocação de recursos determinada pela capacidade instalada, retirando dos gestores estaduais e municipais do SUS qualquer poder na definição do processo alocativo (MARQUES; MENDES, 2003).

Esta NOB introduziu a relação direta do Ministério da Saúde com as secretarias municipais de saúde através de convênios de municipalização, convênios que transformavam os serviços de natureza pública municipais - em prestadores ressarcidos financeiramente de acordo com a produção. Introduziu, também, critérios de transferências de recursos do Ministério da Saúde somente por remuneração da produção de serviços, inibindo a autonomia gestora dos governos locais. Isto porque os recursos de assistência à saúde, quando creditados para as unidades ambulatoriais e hospitalares prestadoras de serviços, não podiam ser executados diretamente pelos municípios/secretarias de saúde (BRASIL, 1991). Pela NOB 91, os municípios eram transformados em entidades produtoras de procedimentos de assistência médica, igualando-se àquelas de natureza privada e filantrópica (MARQUES; MENDES, 2003).

A NOB 93 (BRASIL, 1993) estabelece a relação entre o grau de municipalização correspondente à condição de gestão do sistema local de saúde e sua responsabilidade no SUS. Direcionou-se ao resgate do processo de descentralização do sistema ao estabelecer três níveis de autonomia de gestão infranacionais, ou seja, condições de gestão incipiente, parcial e semiplena. Foi pactuado também que a descentralização deveria ser um processo lento e gradual, com liberdade de adesão por parte das unidades federadas e que as 
instâncias locais de governo se habilitariam institucional e tecnicamente a adquirir maior grau de autonomia de gestão (UGÁ; MARQUES, 2005).

Os enquadramentos dos municípios às condições de gestão eram aprovados pelas novas arenas de pactuação institucionalizadas pela NOB 93, as CIBs, em cada estado e com representantes seus e do conjunto de municípios, por meio dos Conselhos Estaduais de Secretários Municipais de Saúde (COSEMS), e a CIT, âmbito federal, com representantes do Ministério da Saúde, do conjunto dos estados por meio do Conselho Nacional de Secretários Estaduais de Saúde (CONASS) e dos municípios por meio dos COSEMS (BRASIL, 1993).

Para tanto, os municípios recebiam mensalmente, de forma automática, fundo a fundo (Fundo Nacional de Saúde para o Fundo Municipal de Saúde), o montante de recursos financeiros correspondentes a um teto financeiro estabelecido para o custeio de atividades ambulatoriais, hospitalares, por meio de recursos federais realizados por sua própria rede e pela rede contratada de forma suplementar (BRASIL, 1993).

Trevisan e Junqueira (2007) destacam que essa NOB marca os primeiros passos de uma descentralização administrativa do sistema de saúde, estabelecendo formas rígidas de manutenção das estruturas de financiamento, em instância federal. A partir da NOB de 1993, o SUS convive com dois instrumentos de gestão: o primeiro é o que estabelece o subsídio à demanda, através de um sistema de pré-pagamento per capita; o segundo mantém o tradicional sistema de manutenção do subsídio à oferta por meio da remuneração por produção.

A rigor, esses dois instrumentos de gestão estabeleceram uma divisão operacional: no primeiro ficou a responsabilidade com a atenção básica e a média complexidade; no segundo, a referência ambulatorial e hospitalar. Na prática, a atenção básica reteve o papel de subsistema de entrada e controle, adotando o sistema inovador de pré-pagamento, enquanto o outro subsistema, que inclui o atendimento de maior complexidade e ambulatorial, manteve a tradicional remuneração por serviço prestado (PREUSS, 2011).

A NOB 96, editada em 05 de novembro de 1996 por meio da portaria GM/MS nº 2.203 (BRASIL, 1996), com o intuito de consolidar e aprofundar os avanços na direção da descentralização,

[...] previa duas formas de gestão para o subsistema por pré-pagamento: a gestão plena de atenção básica e a plena do sistema de saúde, que substituiriam todas as disposições anteriores. Para a gestão plena de atenção básica, cabia ao município elaborar a programação municipal dos serviços básicos, gerenciar as unidades laboratoriais próprias, prestar ou acompanhar os serviços relacionados à atenção básica e executar as ações básicas de vigilância sanitária e epidemiológica. Era obrigatório comprovar o funcionamento do Conselho Municipal de Saúde, operar o Fundo Municipal de Saúde e ter um Plano Municipal de Saúde. Satisfeitas tais condições, os benefícios alcançados incluíam a obtenção das transferências diretas dos recursos federais ao município, bem como o de ter as unidades básicas de saúde no território do município, estatais ou privadas, subordinadas à gestão municipal. (TREVISAN; JUNQUEIRA, 2007, p. 898).

A Norma introduziu, também, um processo de programação pactuada e integrada entre as três esferas de governo das atividades de assistência ambulatorial e hospitalar, de vigilância sanitária e de epidemiologia e controle de doenças, construindo um novo modelo de atenção com ênfase à promoção da saúde e à atenção básica. Nesta forma de gestão, o Ministério da Saúde é quem efetua, ainda, pagamento direto aos prestadores estatais e privados (contratados e conveniados) por serviços realizados conforme programação e mediante prévia autorização do gestor. Referem-se a procedimentos ambulatoriais de média complexidade e tratamento fora do domicílio (BRASIL, 1996).

Com esse novo modelo assistencial houve mudanças no sistema de transferências intergovernamentais, através do Piso de Atenção Básica (PAB). Estas consistiram na criação de um valor per capita nacional para o custeio de procedimentos de atenção básica, correspondentes aos procedimentos de assistência básica e na criação de incentivos financeiros para a implantação de programas e ações específicos. $\mathrm{O}$ financiamento de média e alta complexidade ambulatorial, medicamentos e insumos excepcionais mantiveram a estrutura de remuneração por serviços produzidos, exceto para os municípios em gestão plena de sistema que recebiam fundo a fundo, nos limites do teto financeiro da assistência para eles estabelecidos, os recursos para este campo de provisão do sistema. Salienta-se ainda que, no âmbito do SUS, é este o modelo de alocação intergovernamental de recursos que vigora até os dias atuais (UGÁ; MARQUES, 2005).

O processo de municipalização da saúde se consolidou a partir da NOB de 1996, sendo o município o responsável imediato pelo atendimento das necessidades e demandas de seu povo e das exigências de intervenções saneadoras em seu território (BRASIL, 1996). Esta NOB, ao mesmo tempo em que determina relações de independência do município como gestor pleno, inibe sua autonomia no papel de gestor único do sistema local ao introduzir a adoção de incentivos, campanhas e recursos financeiros à implantação de programas federais - Programa de Agentes Comunitários de Saúde (PACS) e Programa de Saúde da Família (PSF), não definidos no âmbito local. 
A elevada taxa de adesão dos governos locais à NOB/96 é, sem dúvida, expressão dos efeitos cumulativos do longo processo de implantação da descentralização na saúde no Brasil, mas também - e principalmente - dos incentivos à adesão envolvidos em suas regras. A possibilidade de escolhas para a habilitação permaneceu, envolvendo a possibilidade de evitar a dimensão mais complexa e conflituosa da gestão local dos serviços de saúde, relacionada à gestão da média e alta complexidade. Além disso, apenas $2 \%$ dos municípios tinham um $\mathrm{PAB}$ per capita superior ao da NOB/96 e, portanto, tiveram perdas com a nova regra de distribuição das transferências; $66 \%$ tiveram ganhos e, para $22 \%$, a mudança da regra foi neutra (COSTA et al., 1999). Finalmente, na implementação da NOB/96, o Ministério da Saúde foi capaz de conferir credibilidade ao cumprimento de seus compromissos com os governos locais. (ARRETCHE, 2003, p. 341).

Desta forma, deu-se continuidade à descentralização da gestão de saúde com a edição da NOAS-SUS 01/ 2001 (BRASIL, 2001). Esta portaria teve como objetivo aprofundar o processo de regionalização como forma de "garantir o acesso a todas as ações e serviços de saúde necessários, otimizando os recursos disponíveis". (BRASIL, 2001, p. 23). Avança no processo de responsabilização dos gestores estaduais e municipais pela atenção integral aos seus cidadãos e está assentada em três estratégias principais: a regionalização da assistência; o fortalecimento da capacidade de gestão do SUS; e a atualização dos critérios de habilitação de estados e municípios. Tais estratégias correspondem às seguintes ações:

A NOAS/SUS/01 determina que cabe às secretarias estaduais de saúde elaborar o Plano Diretor de Regionalização para garantir acesso ao cidadão, o mais próximo possível à residência de um 'conjunto mínimo de ações e serviços', estabelecendo também o compromisso entre os municípios para o atendimento de referências intermunicipais. O Plano Diretor de Regionalização obedece alguns pontos básicos como o de 'Módulos Assistenciais', que representam um conjunto de municípios que atuam referenciados a um 'município-sede' que está apto a oferecer um elenco de serviços de média complexidade. Há um municípiopolo que atende os demais do módulo em qualquer nível de atenção. Os módulos constituem regiões e microrregiões de Saúde conforme as suas possibilidades de atendimento. A operacionalização da regionalização pertence às Secretarias Estaduais de Saúde a quem cabe coordenar todas as mudanças. (TREVISAN; JUNQUEIRA, 2007, p. 899).

De forma geral, a NOAS-SUS 01/2001 (BRASIL, 2001) promoveu a redefinição das funções das esferas de governo e fragmentou a gestão do sistema segundo níveis de complexidade da assistência e atenção do sistema - básica, média e alta complexidade, diminuindo assim o poder de decisão do gestor municipal sobre determinadas áreas do sistema (MARQUES; MENDES, 2003).

O Plano Diretor de Regionalização (PDR) é um instrumento de ordenamento do processo de regionalização da assistência em cada estado e no Distrito Federal, baseia-se nos objetivos de definição de prioridades de intervenção, de acordo com as necessidades de saúde da população e garantia de acesso dos cidadãos a todos os níveis de cuidado. O estado é a instância de competência para elaboração do PDR, em consonância ao Plano Estadual de Saúde, passando a assumir, assim, uma maior responsabilidade na gestão do SUS (BRASIL, 2001).

A partir da organização da regionalização em saúde, à maioria dos municípios brasileiros, coube a elaboração de planos e programas para a assistência à saúde, em bases não coincidentes com o seu território e sua autonomia política administrativa. Através dessa forma de regionalização, a autonomia municipal na gestão de saúde acabou reduzida, diferentemente do que consta no artigo 198 da Constituição Federal de 1988, onde as ações e serviços de saúde "integram uma rede regionalizada e hierarquizada e constituem um sistema único". (BRASIL, 2001, p. 23).

A NOAS-SUS 01/2001 foi aperfeiçoada em alguns aspectos e substituída pela NOAS-SUS 01/2002. Tanto a NOAS-SUS 01/2001 (BRASIL, 2001) como a NOAS-SUS 01/2002, instituída pela portaria GM/MS n ${ }^{\circ}$ 373, de 27 de fevereiro de 2002 (BRASIL, 2002) tem o mesmo objetivo: de um lado, efetivar a regionalização do sistema de saúde, fortalecendo o acesso e a integralidade da atenção à saúde, especialmente no tocante à melhoria do fluxo dos níveis de média e alta complexidade; e, de outro, manter a responsabilidade dos serviços de alta complexidade nas mãos do governo federal. A NOAS-SUS 01/2002, ao garantir as diretrizes de organização do sistema definidas pela NOAS-SUS 01/2001, oferece alternativas à superação dos constrangimentos e impasses evidenciados no período de implementação entre elas.

Através desta Norma, o PDR constitui-se num instrumento de organização dos territórios estaduais em regiões e microrregiões e módulos assistenciais; de conformação de redes hierarquizadas de serviços; de estabelecimento de mecanismos e fluxos de referência e contra referência intermunicipais, com o objetivo de garantir a integralidade da assistência e o acesso da população aos serviços e ações de saúde de acordo com suas necessidades. A partir do PDR, elaboraram-se as PPI anuais (BRASIL, 2002). 
Nos primeiros anos do século XXI, além da NOAS-SUS 01/2001 foram publicadas as versões 2002 (BRASIL, 2001, 2002) e em 2006, as portarias relativas ao Pacto pela Saúde (BRASIL, 2006b, 2006c). O Pacto pela Saúde contempla o acordo firmado entre os gestores do SUS, em suas três dimensões: pela Vida, em Defesa do SUS e de Gestão. De forma geral, o Pacto pela Saúde estabelece que esse acordo seja feito com base na formalização de compromissos que compreendem responsabilidades sanitárias e de gestão, e a pactuação de metas prioritárias relacionadas a indicadores que possam servir para o controle mútuo, o monitoramento e a avaliação dos compromissos assumidos (PREUSS, 2011).

As normas operacionais foram importantes instrumentos e contribuíram para descentralizar as ações e serviços de saúde, contudo, também, criaram obstáculos aos municípios e à descentralização, pois exigiam o cumprimento de regras nem sempre compatíveis com sua realidade local, bem como não consideravam a diversidade do território brasileiro, suas características locais e regionais, como as regiões de fronteiras.

Os municípios brasileiros, com distintas dimensões geográficas, apresentam estrutura econômico-social heterogênea, especificidades no que se refere à região, ao porte, à capacidade de gestão e distância a um centro regional ou capital. Tais características repercutem diretamente em ações, serviços e, principalmente na gestão da saúde. É diante deste contexto que a proposição do Pacto pela Saúde, substituindo a normatização excessiva e superando a lógica da habilitação, propõe uma nova forma de pactuação de compromisso com a realização de um conjunto de ações e com seus resultados, conforme a realidade de cada município.

\section{O Pacto pela Saúde e as regiões de fronteiras}

O Pacto pela Saúde, publicado na Portaria/GM no 399, de 22 de fevereiro de 2006 (BRASIL, 2006b), contempla o Pacto firmado entre os gestores - União, Estados e Municípios do SUS, em três dimensões: pela Vida, em Defesa do SUS e de Gestão. O Ministério da Saúde, o Conselho Nacional de Secretários de Saúde (CONASS) e o Conselho Nacional de Secretários Municipais de Saúde (CONASEMS), pactuaram responsabilidades entre os três gestores do SUS, no campo da gestão do sistema e da atenção à saúde (BRASIL, 2011).

O Pacto pela Vida estabelece compromissos para atingir metas sanitárias entre os gestores do SUS, com base na definição de prioridades que resultem em real impacto no nível de vida e saúde da população brasileira. O Pacto em Defesa do SUS estabelece compromissos polí-ticos envolvendo o Estado e a sociedade civil, objetivando consolidar a Reforma Sanitária Brasileira, nos moldes em que foi inscrito na Constituição Federal. O Pacto de Gestão define as responsabilidades sanitárias das três esferas de gestão (municipal, estadual e federal) para a gestão do SUS, nos aspectos da gestão do trabalho, educação na saúde, descentralização, regionalização, financiamento, planejamento, programação pactuada e integrada, regulação das ações e serviços, monitoramento e avaliação, auditoria e participação e controle social (BRASIL, 2006d).

Trata-se de um conjunto de reformas institucionais, pactuado entre as três esferas de gestão do SUS, com o objetivo de promover inovações nos processos e instrumentos de gestão, a melhoria dos serviços ofertados à população, garantindo, assim, acesso a todos. Sua implementação se dá por meio da adesão de municípios, estados e União ao Termo de Compromisso de Gestão (TCG), que substitui os anteriores processos de habilitação e estabelece metas e compromissos para cada ente da federação. No que se refere à transferência dos recursos, estes passam a ser divididos em seis blocos de financiamento (Atenção Básica, Média e Alta Complexidade da Assistência, Vigilância em Saúde, Assistência Farmacêutica, Gestão do SUS e Investimentos em Saúde) (PREUSS, 2011).

Esta implementação apresenta muitas mudanças na execução do SUS, dentre as quais se destacam: a Regionalização solidária e cooperativa como eixo estruturante do processo de Descentralização; a Integração das várias formas de repasse dos recursos federais; e a Unificação dos vários pactos hoje existentes.

Anterior à construção do Pacto pela Saúde, os processos de gestão do SUS eram orientados por NOBs e NOAS, elaboradas a partir da década de 1990 e que hoje não contemplam o atual cenário da política de saúde brasileiro. As Normas editadas foram de encontro à verdadeira proposta da descentralização, gerando no sistema uma dependência da emissão de portarias ministeriais. Observa-se, ainda, que se privilegiou o repasse dos recursos financeiros predestinados, estes somente podem ser usados para determinada atividade, programa ou serviço em saúde, não respeitando e considerando as prioridades locais, sobrecarregando os municípios devido às múltiplas contas com recursos de várias naturezas.

As críticas direcionadas ao sistema de habilitação dos municípios criado por essas normas recaíram sobre as desigualdades de autonomia de gestão entre os municípios, que acentuavam ainda mais as desigualdades em saúde existentes no país. Por outro lado, essas críticas estendiam-se às limitações dos planos municipais de saúde reduzidos à formalidade, uma vez que toda a dinâmica da fragmentação do financiamento fortalecia a verticalização do sistema e o engessamento da gestão. O repasse de recursos fragmentados 
por programa ou ação de saúde era dependente da adesão dos municípios ao respectivo programa ou ação, aos quais uma determinada modalidade de gestão tinha ou não acesso. (BRASIL, 2006d, p. 13).

Apesar dos avanços e conquistas com a implantação do SUS, ainda persistem os problemas de saúde e gestão, entre outros, em todas as esferas de governo e que precisam ser enfrentados e superados. Para isso, foram estabelecidos e negociados processos que criam inovações no modelo de gestão para o sistema, mudando as formas de financiamento e repasse dos recursos, bem como um apelo para mobilização da sociedade em defesa do direito à saúde e do SUS.

O Pacto pela Saúde é o resultado do processo de negociação entre os gestores das três esferas de governo, na perspectiva de superação de problemas políticos, técnicos e administrativos para uma participação mais efetiva e autônoma dos municípios na gestão do SUS.

O Ministério da Saúde, na série de publicações Dialogando sobre o Pacto pela Saúde, 2006, conceitua o Pacto pela Saúde como um acordo assumido entre os gestores responsáveis pela implementação do Sistema Único de Saúde, ou seja, os secretários municipais, estaduais, do Distrito Federal e o Ministro da Saúde, com o objetivo de estabelecer novas estratégias na gestão, no planejamento e no financiamento do sistema de forma a avançar na consolidação do SUS, envolvendo ainda o compromisso de ampliar a mobilização popular e o movimento em defesa do SUS (PREUSS, 2011).

A finalidade maior do Pacto é promover a melhoria na quantidade e qualidade dos serviços ofertados à população e a garantia do acesso de todos a esses serviços. Nele estão previstas ações de cooperação técnica e solidária entre as secretarias municipais de saúde, as secretarias estaduais de saúde, do Distrito Federal e o Ministério da Saúde, favorecendo a construção de novos mecanismos que ampliem e qualifiquem a gestão pública dos sistemas e serviços de saúde.

Espera-se, enquanto expectativas e resultados, que o Pacto pela Saúde possa ser um instrumento para consolidar uma gestão do SUS cooperativa e articulada, respeitando as diferenças regionais, fortalecendo o papel de articulação e negociação dos gestores municipais, estaduais e federal, mobilizados para elaborar metas, desenvolver ações e assumir responsabilidades no processo de implementação do SUS. Importante, também, que seja coerente com as necessidades de saúde e com a capacidade de gestão de cada lugar, pois pode ser reformulado nos próximos anos de acordo com os novos desafios que se apresentarem na saúde, tendo como base a pactuação feita de forma dialogada (BRASIL, 2006a).

O Pacto de Gestão estabelece, de forma negociada, as responsabilidades das secretarias municipais, estaduais, do Distrito Federal e do Ministério da Saúde, tornando mais evidente as responsabilidades de cada uma dessas esferas, contribuindo, assim, para o fortalecimento da gestão compartilhada e solidária do SUS. A gestão do SUS se traduz em políticas e recursos para formar e capacitar pessoas para essas funções e apoiar as melhorias que são necessárias na gestão (BRASIL, 2006d).

Visando dar outra operacionalidade para efetiva descentralização da saúde, constrói-se o Pacto de Gestão:

Integralizar as ações do sistema é, exatamente, construir o 'pacto de gestão'. A formulação desse pacto facilita a identificação de situações essenciais tanto para o gestor do sistema, como para os trabalhadores da saúde e, claro, para o usuário da rede. $\mathrm{O}$ aspecto mais relevante da arquitetura do pacto de gestão é a que permite identificar critérios de necessidades para o bom funcionamento do sistema. É só no âmbito de um 'pacto' que é possível, realmente, perceber, prever e administrar o risco à saúde individual e coletiva. Os determinantes sociais e a visão positiva da saúde emergem com mais eficácia na lógica de um 'pacto' e não da gestão por instância de poder, ainda que integradas. É preciso ter absoluta clareza que não existe o doente federal, estadual, municipal ou comunitário. Existe o cidadão que está exercendo o direito constitucional de ter acesso à saúde, que o sistema único deve oferecer. (TREVISAN; JUNQUEIRA, 2007, p. 899).

O Pacto define as diretrizes e responsabilidades para a gestão do sistema, contribuindo para o fortalecimento desta, em cada um dos eixos de ação, estabelecendo as prioridades: definir de forma clara a responsabilidade em saúde de cada instância gestora do SUS: federal, estadual e municipal e; estabelecer as diretrizes para a gestão do SUS, com ênfase em: Descentralização; Regionalização; Financiamento do SUS; Planejamento no SUS; Programação Pactuada Integrada (PPI); Regulação da Atenção à Saúde e Regulação Assistencial; Monitoramento e Avaliação da Gestão; Participação e Controle Social; Gestão do Trabalho na Saúde; Educação na Saúde (BRASIL, 2006d).

A regionalização, em pauta neste artigo, objetiva reduzir as desigualdades sociais e territoriais através da identificação das regiões de saúde. Dentre seus pressupostos, destacam-se a territorialização e a flexibilidade. A territorialização é situada enquanto apropriação dos espaços locais, das relações estabelecidas com os sujeitos, das situações regionais e de suas peculiaridades. A flexibilidade no respeito à diversidade, a 
heterogeneidade territorial brasileira que revela as especificidades estaduais, regionais, municipais e suas dinâmicas distintas, como as regiões de fronteira.

Para melhorar e facilitar o acesso aos distintos serviços de saúde é necessário que sejam criadas as regiões de saúde. Estas devem ser consideradas e definidas de acordo com o cotidiano dos sujeitos e das comunidades, acompanhando a existência dos serviços de saúde no local onde moram e transitam. A criação das regiões de saúde requer negociações que envolvam as três esferas de governo, cada qual com seus compromissos e responsabilidades atinentes ao seu território e cidadãos (PREUSS, 2011).

A regionalização tem como meta orientar a descentralização das ações e serviços de saúde e os processos de negociação e pactuação entre os gestores. Os principais instrumentos de planejamento da Regionalização são o Plano Diretor de Regionalização (PDR), o Plano Diretor de Investimento (PDI) e a Programação Pactuada e Integrada da Atenção à Saúde (PPI), no documento (PREUSS, 2011).

Dentre os objetivos da regionalização, destacam-se: garantir acesso, resolutividade e qualidade às ações e serviços de saúde cuja complexidade e contingente populacional transcendam a escala local/municipal; garantir o direito à saúde, reduzir desigualdades sociais e territoriais e promover a equidade; garantir a integralidade na atenção à saúde, ampliando o conceito de cuidado à saúde no processo de reordenamento das ações de promoção, prevenção, tratamento e reabilitação com garantia de acesso a todos os níveis de complexidade do sistema; potencializar o processo de descentralização, fortalecendo estados e municípios para exercerem papel de gestores e para que as demandas dos diferentes interesses locorregionais possam ser organizadas e expressadas na região (BRASIL, 2006a).

Nesta diretriz são consideradas regiões de saúde os recortes territoriais de um espaço geográfico contínuo, identificadas pelos gestores municipais e estaduais a partir de identidades culturais, econômicas e sociais, de redes de comunicação e infraestrutura de transportes compartilhados do território. De acordo com As Diretrizes Operacionais - Pactos pela Vida, em Defesa do SUS e de Gestão (BRASIL, 2006d, p. 20-21, grifo nosso), as regiões podem ter os seguintes formatos:

I. Regiões Intraestaduais, compostas por mais de um município, dentro de um mesmo estado; II. Regiões Intramunicipais, organizadas dentro de um mesmo município de grande extensão territorial e densidade populacional; III. Regiões Interestaduais, conformadas a partir de municípios limítrofes em diferentes estados; IV. Regiões Fronteiriças, conformadas a partir de municípios limitrofes com países vizinhos.

Nos casos das regiões fronteiriças, o Ministério da Saúde deve promover articulação entre os países e órgãos envolvidos, na implementação do sistema de saúde e organização da atenção nos municípios fronteiriços, coordenando e fomentando a constituição dessas Regiões e participando do Colegiado de Gestão Regional.

O Pacto pela Saúde (BRASIL, 2006b), portanto, avança nesta perspectiva ao apontar a regionalização como o eixo estruturante de uma de suas três dimensões - Gestão do SUS, contemplando também as regiões de fronteira. A regionalização objetiva reduzir as desigualdades sociais e territoriais através da identificação das regiões de saúde. Dentre seus pressupostos destacam-se a territorialização e a flexibilidade. A territorialização é situada enquanto apropriação dos espaços locais, das relações estabelecidas com os sujeitos, das situações regionais e de suas peculiaridades. A flexibilidade no respeito à diversidade, a heterogeneidade territorial brasileira que revela as especificidades estaduais, regionais, municipais e suas dinâmicas distintas, como as regiões de fronteira (PREUSS, 2011).

Destaca-se, ainda, a inclusão no Pacto pela Saúde, de financiamento diferenciado, para o desenvolvimento de ações e serviços sanitários nos municípios de fronteira - uma característica inovadora no aspecto de gestão.

As regiões de saúde foram e são criadas para garantir a integralidade da atenção à saúde, garantindo ao cidadão uma rede de proteção e cuidado, na atenção básica, nos ambulatórios, nos hospitais e demais ações e serviços de saúde. Elas são consideradas recortes territoriais inseridas em um espaço geográfico contínuo, identificadas pelos gestores municipais e estaduais, com base em identidades culturais, econômicas e sociais, de redes de comunicação e infraestrutura de transportes compartilhados do território e da realidade sanitária (PREUSS, 2011).

As regiões devem organizar a rede de ações e serviços de saúde, a fim de assegurar aos cidadãos o cumprimento dos princípios constitucionais de universalidade do acesso, equidade e integralidade do cuidado, favorecer a ação cooperativa e solidária entre os gestores dos vários municípios que poderão estar envolvidos na região e os gestores estaduais de saúde, bem como o fortalecimento do controle social (PREUSS, 2011).

Para melhorar o processo de regionalização, buscando o cumprimento e o aprimoramento dos princípios do SUS, os gestores de saúde da região deverão constituir um espaço permanente de negociação e pactuação, por meio de um colegiado de gestão regional, abrangendo os gestores dos municípios que compõem a região. A denominação e o funcionamento do colegiado devem ser acordados na CIB e submetidos à 
aprovação dos conselhos de saúde. O colegiado de gestão regional se constitui num espaço de decisão no qual são identificados os problemas, definidas as prioridades e pactuadas as soluções para a organização de uma rede regional de ações e serviços de atenção à saúde, integrada e resolutiva. (BRASIL, 2006a, p. 31).

O Pacto de Gestão assume o desafio de avançar na regionalização e descentralização do SUS, com base em seus princípios, mas operacionalizando-os de forma a respeitar as especificidades regionais, fortalecendo a solidariedade e cooperação entre os municípios e entre gestores, apoiando e qualificando a participação popular. Nesse processo, cabe ao Ministério da Saúde a proposição de políticas, a participação no cofinanciamento, a cooperação técnica, a avaliação, a regulação, o controle e a fiscalização, além da mediação de conflitos porventura existentes (BRASIL, 2006a).

Em 29 de junho de 2011, foi publicado no Diário Oficial o Decreto Presidencial n ${ }^{\circ} 7.508$, regulamentando a Lei n ${ }^{\circ} 8.080$ de 1990 (BRASIL, 2011), que dispõe sobre a organização do SUS, o planejamento da saúde, a assistência à saúde e a articulação interfederativa, e dá outras providências. O Decreto regula a estrutura organizativa do SUS, garantindo maior segurança jurídica para o gestor, definindo as responsabilidades das três esferas de gestão e reafirmando o papel do controle social no estabelecimento de diretrizes para o planejamento no SUS. Aspectos estes já preconizados no Pacto pela Saúde (BRASIL, 2006a).

\section{As normas operacionais foram} importantes instrumentos e contribuíram para descentralizar as ações e serviços de saúde, contudo, também, criaram obstáculos aos municípios e à

\section{descentralização, pois exigiam}

o cumprimento de regras nem sempre compatíveis com sua realidade local, bem como não consideravam a diversidade do território brasileiro, suas características locais e regionais, como as regiões de fronteiras.

A partir deste Decreto, os serviços de saúde oferecidos devem ser organizados na Região de Saúde, em Redes de Atenção à Saúde, buscando fortalecer as ações interfederativas através de princípios para organização da rede regionalizada de serviços de saúde. O Decreto cria dispositivos e introduz novos conceitos na organização do SUS (BRASIL, 2011).

Os novos conceitos visam qualificar a gestão do sistema, dentre eles o da Região de Saúde; ordena e ratifica uma nova conformação na organização do Sistema a partir da formatação da Região de Saúde, da definição do que são Portas de Entrada às ações e aos serviços de saúde nas Redes de Atenção à Saúde; e por fim, do acesso universal e igualitário à assistência farmacêutica. Especificamente, no que se refere às regiões fronteiriças, no art. $4^{\circ}, \S 2^{\circ}$, a instituição de Regiões de Saúde situadas em áreas de fronteira com outros países deverá respeitar as normas que regem as relações internacionais (BRASIL, 2011).

A proximidade, a identidade e a capacidade de governo das municipalidades, em cooperação com os governos estadual e federal, são condições necessárias à coesão entre os agentes políticos e sociais de uma Região de Saúde. Diante disso, o fortalecimento da descentralização exige ênfase na importância dos espaços locorregionais e na definição das competências das três esferas de governo, contexto em que estados e municípios assumem relevância estratégica (BRASIL, 2006a).

Portanto, o projeto de regionalização, evidenciado com o Pacto pela Saúde (BRASIL, 2006), desempenha papel importante, pois, ao contemplar regiões fronteiriças, objetiva, além de assegurar o cumprimento dos princípios constitucionais universalidade, equidade e integralidade das ações e serviços de saúde, amplia a capacidade operacional dos municípios.

No entanto, tais conquistas, na contemporaneidade, tem sido ameaçadas pela ofensiva do capital, inviabilizando sua plena implementação. A política de saúde tem sido tencionada pelos interesses do capital, que vem ampliando formas de privatização e impondo obstáculos à garantia do direito universal à saúde. Reduz a saúde "como acesso a procedimentos, ao consumo individual de atos médicos capazes de gerar lucros, negligenciando e secundarizando ações e práticas de promoção, proteção e prevenção da saúde". (PAIVA; COSTA, 2016, p. 53).

É neste cenário, de ofensivas do capital, que os rebatimentos do conflito entre capital e trabalho apresentam novas expressões ${ }^{2}$, influenciando decisivamente nos rumos da política de saúde e, consequentemente em sua gestão. Novos modelos de gestão, que seguem tendências de privatização, são apresentados para as saídas apontadas à precarização da política de saúde. Dentre os novos modelos, destacam-se as Organiza- 
ções Sociais (OS); Organizações Sociais de Interesse Público (OSCIP); Fundações de Direito Privado; e, por fim, a Empresa Hospitalar de Serviços Hospitalares (EBSERH) (PAIVA; COSTA, 2016, p. 53).

A proposta de política de saúde como direito e dever do Estado, democrática, universal, construída a partir do Movimento Sanitário, consolidada na Constituição Federal de 1988 (BRASIL, 2016a) e nas diferentes Normativas e Pactos aqui abordados (BRASIL, 1991, 1993, 1996, 2006b, 2006c), está sendo substituída por uma política de caráter privado e mercantilista.

Tal fato pode ser observado na alteração das legislações vigentes, como é o caso da Emenda Constitucional $n^{\circ} 95$, de 15 dezembro de 2016 (BRASIL, 2016b), que congelou por 20 anos os recursos destinados às políticas sociais e na revisão da Política Nacional de Atenção Básica (PNAB). A nova PNAB, aprovada em agosto de 2017 e publicada em Diário Oficial através da portaria 2.436/2017 (BRASIL, 2017), substitui a lei anterior, de 2011, e modifica a Estratégia Saúde da Família (ESF) e o Programa de Agentes Comunitários de Saúde (PACS).

Uma das principais mudanças introduzidas pela nova PNAB refere-se ao papel da ESF, inserida na Atenção Básica como rede ordenadora. Entende-se que, de acordo com a portaria, a ESF deixa de ser prioridade, pois é considerada opcional e são criados dois tipos de equipes: a de Saúde da Família (eSF) e a de Atenção Básica (eAB). Estas mudanças, de cunho mercadológico, impactam no orçamento da política de saúde, repercutindo significativamente na gestão da política nos municípios, na oferta de serviços e programas e afetando gestores, profissionais e usuários do SUS.

\section{Considerações finais}

Analisando as Normativas e o Pacto pela Saúde aqui apresentados, pode-se concluir que o Pacto tornou-se o novo instrumento para a gestão compartilhada do SUS, reconhecendo-se a autonomia municipal mediante a extinção das habilitações que, de certa forma, denotavam o consentimento do Ministério da Saúde para que municípios ou estados fossem reconhecidos como gestores da saúde em seus territórios.

Em substituição à habilitação, foi instituído o Termo de Compromisso, instrumento que formaliza os acordos e os pactos entre os gestores da saúde. As normas operacionais, que regulamentavam as habilitações, eram regras de organização e financiamento do SUS ditadas e editadas pelo Ministério, detalhavam os procedimentos a serem observados pelos estados e municípios interessados nas transferências financeiras federais. Acompanhadas por um conjunto de outras portarias, cada qual com contribuições específicas para os avanços na saúde, introduziram-se novas formas de relação entre os gestores e novos formatos de alocação de recursos no setor.

No Pacto pela Saúde (BRASIL, 2006b) observam-se elementos de continuidade em relação às orientações e normativas anteriores, principalmente no que se refere ao poder de regulação do Ministério da Saúde, e mudança ao contemplar na regionalização os territórios fronteiriços, permanecendo, assim, o desafio de reconfigurar o modelo de pactuação até então vigente. Caso contrário, o Pacto é apenas mais um instrumento normativo.

A descentralização da política de saúde no Brasil é perpassada por complexas relações entre as três esferas de governo. Entende-se que historicamente o Governo Federal vem exercendo um papel indutor, através de mecanismos de transferências de recursos financeiros para os municípios em função de sua adesão às normativas e ao Pacto pela Saúde. É importante ressaltar que, anterior ao Pacto, as políticas e programas federais foram reguladas e operacionalizadas por meio de inúmeras portarias atreladas a mecanismos de financiamento.

A tensão histórica e contraditória entre centralização e descentralização ainda está presente no âmbito da gestão da política da saúde. Pode-se constatar que, embora tenha ocorrido um aumento da capacidade gerencial dos municípios no SUS e as três esferas de governo, autônomas e interdependentes, tenham definido suas competências e responsabilidades, a saúde é responsabilidade do município.

Ou seja, a descentralização vem se configurando como uma transferência de gestão, em seus aspectos burocráticos, administrativos e gerenciais, de forma tutelada e apressada. Tanto a descentralização como a regionalização previstas no Pacto de Gestão, não garantiram maior autonomia aos governos locais, pois não houve transferência efetiva de poder decisório na gestão. Delegou uma maior responsabilidade à gestão municipal, ou seja, há uma maior responsabilização do município neste cenário.

No que se refere às regiões de fronteiras, o questionamento é se realmente foram incorporadas as alterações propostas pelo Pacto. O exercício das novas competências, previstas pelo Pacto, passa pela capacidade efetiva dos municípios exercerem a sua autonomia na gestão da saúde. E, nesse sentido, a gestão está relacionada às questões culturais, sociais, econômicas, demográficas, localização geográfica, competência técnica-administrativa, de disponibilidades de recursos financeiros e tecnológicos para garantir o direito à saúde de seus munícipes.

A inclusão no Pacto pela Saúde de financiamento diferenciado para o desenvolvimento de ações e serviços sanitários nos municípios de fronteira é um grande avanço. Em suas três dimensões, o Pacto contempla algumas 
estratégias já consolidadas pelos gestores do SUS, respeitando as diferenças regionais, além de agregar os pactos já existentes, reforçando a organização das regiões por meio de mecanismos de gestão e planejamento.

Ou seja, considerando as identidades e características regionais tão diversas é fundamental que haja flexibilidade no processo de configuração das regiões de saúde. Esses arranjos territoriais, portanto, devem possibilitar, também, a estruturação de regiões nas faixas territoriais fronteiriças com outros países latino-americanos.

As estratégias de descentralização e regionalização preconizadas no Pacto pela Saúde (BRASIL, 2006a) podem ser importantes ferramentas para a melhoria do provimento de serviços e garantia de direitos à saúde especialmente as regiões de fronteiras. Porém, deve-se ter clareza que devido às diversidades territoriais brasileiras e a capacidade efetiva, nem todos os municípios possuem condições de implementá-las. Para além destas questões postas, o desmonte financeiro do SUS tem-se constituído no maior empecilho para concretização da descentralização e regionalização.

\section{Referências}

ARRETCHE, M. Financiamento federal e gestão local de políticas sociais: o difícil equilíbrio entre regulação, responsabilidade e autonomia. Ciências \& Saúde Coletiva, Rio de Janeiro. v. 8, n. 2, p. 331-345, 2003. Disponível em: <http://www.scielo.br/pdf/csc/v8n2/ a02v08n2.pdf>. Acesso em: 04 jun. 2009.

BRASIL. Constituição (1988). Emenda constitucional no 95, de 15 de dezembro de 2016. Altera o Ato das Disposições Constitucionais Transitórias, para instituir o Novo Regime Fiscal, e dá outras providências. Diário Oficial da União, Brasília, DF, 16 dez. $2016 \mathrm{~b}$. Disponível em: $<$ http://pesquisa.in.gov.br/imprensa/jsp/visualiza/index.jsp?data=16/12/2016\&jornal=1\&pagina=2\&totalArquivos=368> . Acesso em: 12 mar. 2018.

. Instituto Nacional de Assistência Médica da Previdência Social. Resolução n 258, de 07 de janeiro de 1991. Nova política de financiamento do SUS para 1991. Norma Operacional Básica nº1/91. Diário Oficial [da] República Federativa do Brasil, Brasília, DF, 10 jan. 2007. Disponível em: <http://pesquisa.in.gov.br/imprensa/jsp/visualiza/index.jsp?data=10/01/ 1991\&jornal=1\&pagina=49\&totalArquivos=136>. Acesso em: 04 jun. 2009.

. Ministério da Saúde. Gabinete do Ministro. Portaria no 95, de 26 de janeiro de 2001. Norma Operacional de Assistência à Saúde / SUS. NOAS-SUS 01/2001. Diário Oficial [da] República Federativa do Brasil, Brasília, DF, 29 jan. 2001. Disponível em: <http:// pesquisa.in.gov.br/imprensa/jsp/visualiza/index.jsp?jornal=1\&pagina=23\&data=29/01/2001>. Acesso em: 04 jun. 2009.

. Portaria $\mathrm{n}^{\circ}$ 373, de 27 de fevereiro de 2002. Norma Operacional de Assistência à Saúde / SUS. NOAS-SUS 01/

02. Diário Oficial da União, Brasília, DF, 28 fev. 2002. Disponível em: <http://pesquisa.in.gov.br/imprensa/jsp/visualiza/ index.jsp?jornal $=1 \&$ pagina $=52 \&$ data $=28 / 02 / 2002>$. Acesso em: 04 jun. 2009.

. Portaria n 399, de 22 de fevereiro de 2006. Divulga o Pacto pela Saúde 2006 - Consolidação do SUS e aprova as Diretrizes Operacionais do Referido Pacto. Diário Oficial da União, Brasília, DF, 23 fev. 2006b. Disponível em: <http:// pesquisa.in.gov.br/imprensa/jsp/visualiza/index.jsp?jornal=1\&pagina=43\&data=23/02/2006>. Acesso em: 12 ago. 2010.

. Portaria $n^{\circ} 699$, de 30 de março de 2006. Regulamenta as diretrizes operacionais dos Pactos pela Vida e de Gestão. Diário Oficial da União, Brasília, DF, 03 abr. 2006c. Disponível em: <http://pesquisa.in.gov.br/imprensa/jsp/visualiza/ index.jsp?jornal $=1 \&$ pagina $=49 \&$ data $=03 / 04 / 2006>$. Acesso em: 04 jun. 2009.

. Portaria $\mathrm{n}^{\circ} 545$, de 20 de maio de 1993. Estabelece normas e procedimentos reguladores do processo de descentralização da gestão das ações e serviços de saúdes, através da Norma Operacional Básica - SUS 01/93. Diário Oficial [da] República Federativa do Brasil, Brasília, DF, 24 maio 1993. Disponível em: <http://pesquisa.in.gov.br/imprensa/jsp/visualiza/ index.jsp?.jornal $=1 \&$ pagina $=9 \&$ data $=24 / 05 / 1993>$. Acesso em: 04 jun. 2009.

. Portaria n 2 2.023, de 05 de novembro de 1996. Norma Operacional Básica do Sistema Ùnico de Saúde. NOBSUS 01/96. Diário Oficial [da] República Federal do Brasil. Brasília, DF, 06 nov. 1996. Disponível em: <http://pesquisa.in.gov.br/ imprensa/jsp/visualiza/index.jsp?data=06/11/1996\&jornal=1\&pagina=48\&totalArquivos=96>. Acesso em: 04 jun. 2009.

. Portaria n 2.436, de 21 de setembro de 2017. Aprova a Política Nacional de Atenção Básica, estabelecendo a revisão de diretrizes para a organização da Atenção Básica, no âmbito do Sistema Único de Saúde (SUS). Diário Oficial da União, Brasília, DF, 22 set. 2017. Disponível em: <http://pesquisa.in.gov.br/imprensa/jsp/visualiza/index.jsp?data=22/09/ 2017\&jornal=1\&pagina=68\&totalArquivos=120>. Acesso em: 12 mar. 2018.

. Diretrizes Operacionais dos Pactos pela Vida, em Defesa do SUS e de Gestão. 2. ed. Brasília, DF, 2006d. (Série Pactos pela Saúde 2006, v. 1). Disponível em: <http://bvsms.saude.gov.br/bvs/publicacoes/ PactosPelaVida_Vol1DiretOperDefesaSUSeGestao.pdf $>$. Acesso em: 04 jun. 2009.

Regionalização Solidária e Cooperativa. Brasília, DF: Ministério da Saúde, 2006a. (Série Pactos pela Saúde 2006, v. 3).e Disponível em: <http://bvsms.saude.gov.br/bvs/publicacoes/regionalizacao2006.pdf>. Acesso em: 04 jun. 2009.

. Decreto $\mathrm{n}^{\circ} 7.508$, de 28 de junho de 2011. Regulamenta a Lei $\mathrm{n}^{\circ} 8.080$, de 19 de setembro de 1990, para dispor sobre a organização do Sistema Único de Saúde - SUS, o planejamento da saúde, a assistência à saúde e a articulação interfederativa, e dá outras providências. Diário Oficial da União, Brasília, DF, 29 jun. 2011. Disponível em: <http://www.planalto.gov.br/ccivil_03/_ato2011- 
2014/2011/decreto/d7508.htm>. Acesso em: 12 ago. 2011.

Lei n ${ }^{\circ} 8.142$, de 28 de dezembro de 1990. Dispõe sobre a participação da comunidade na gestão do Sistema Único de Saúde (SUS) e sobre as transferências intergovernamentais de recursos financeiros na área da saúde e dá outras providências. Diário Oficial [da] República Federativa do Brasil, Brasília, DF, 31 dez. 1990. Disponível em: <http://www.planalto.gov.br/ccivil_03/leis/18142.htm>. Acesso em: 12 mar. 2018.

. Constituição da República Federativa do Brasil: texto constitucional promulgado em 5 de outubro de 1988, com as alterações determinadas pelas Emendas Constitucionais de Revisão $n^{\text {os }} 1$ a 6/94, pelas Emendas Constitucionais n ${ }^{\text {os }} 1 / 92$ a 91/2016 e pelo Decreto Legislativo no 186/2008. Brasília, DF: Senado Federal, 2016a. Disponível em: <https://www2.senado.leg.br/bdsf/bitstream/handle/id/ 518231/CF88_Livro_EC91_2016.pdf >. Acesso em: 12 mar. 2018.

MARQUES, R. M.; MENDES, Á. Atenção Básica e Programa de Saúde da Família (PSF): novos rumos para a política de saúde e seu financiamento? Ciência \& Saúde Coletiva, Rio de Janeiro, v. 8, n. 2, p. 403-415, 2003. Disponível em: <http://www.scielo.br/pdf/csc/ v8n2/a07v08n2.pdf $>$. Acesso em: 12 ago. 2011.

PAIVA, A. S. de; COSTA, M. D. H. da. Ataques à política de saúde em tempos de crise do capital. Revista de Políticas Públicas, São Luís, v. 20, n. 1, p. 51-68, jan./jun. 2016. Disponível em: <http://www.periodicoseletronicos.ufma.br/index.php/rppublica/article/view/ 5036/3079>. Acesso em: 12 mar. 2018.

PREUSS, L. T. O pacto pela saúde nas cidades-gêmeas da fronteira do Rio Grande do Sul com a Argentina e o Uruguai. $2011.181 \mathrm{f}$. Tese (Doutorado em Serviço Social)-Pontifícia Universidade Católica do Rio Grande do Sul, Porto Alegre, 2011. Disponível em: <http:/ /tede2.pucrs.br/tede2/handle/tede/498>. Acesso em: 12 mar. 2018.

TREVISAN, L. N.; JUNQUEIRA, L. A. P. Construindo o "pacto de gestão" no SUS: da descentralização tutelada à gestão em rede. Ciência \& Saúde Coletiva, Rio de Janeiro, v. 12, n. 4, p. 893-902, jul./ago. 2007. Disponível em: <http://www.scielo.br/pdf/csc/v12n4/ 08.pdf $>$. Acesso em: 27 abr. 2009.

UGÁ, M. A. D.; MARQUES, R. M. O Financiamento do SUS: trajetória, contexto e constrangimentos. In: LIMA, N. T. et al. (Org.). Saúde e democracia: história e perspectivas do SUS. Rio de Janeiro: FIOCRUZ, 2005. p. 193-233.

\section{Notas}

1 Este artigo tem como referência a tese de doutorado intitulada O pacto pela saúde nas cidades-gêmeas da fronteira do Rio Grande do Sul com a Argentina e o Uruguai, defendida em 2011, junto ao Programa de Pós-graduação em Serviço Social da Pontifícia Universidade Católica do Rio Grande do Sul (PUCRS), sob orientação da professora Doutora Idília Fernandes e coorientadora professora Doutora Vera Maria Ribeiro Nogueira (PREUSS, 2011).É fruto de estudos do projeto de pesquisa docente denominado Atenção primária em saúde no Brasil ena Argentina: um estudo comparado, desenvolvido na Universidade Estadual de Ponta Grossa (UEPG).

2 A reestruturação produtiva, a extinção de postos de trabalho, desemprego, inserção no mercado informal, precarização das relações trabalhistas, questões ambientais, iniquidades em saúde, o não acesso à saúde, dentre outras expressões.

\section{Lislei Teresinha Preuss}

lispreuss@terra.com.br

Doutorado em Serviço Social pela Pontifícia Universidade Católica do Rio Grande do Sul (PUCRS)

Professora Adjunta do Departamento de Serviço Social da Universidade Estadual de Ponta Grossa (UEPG)

\section{UEPG}

Campus Central, Praça Santos Andrade, n. 1

Ponta Grossa - Paraná - Brasil

CEP: 84.030-900

\author{
Agência financiadora \\ Não se aplica.
}

Contribuições dos autores

Não se aplica.

\author{
Consentimento para publicação \\ Não se aplica.
}

Conflito de interesses

Não há conflito de interesses.

Aprovação por Comitê de Ética e consentimento para participação

Não se aplica. 